\title{
Seasonal Unemployment and Voluntary Out-Migration from Northern Bangladesh
}

\author{
Mazbahul Golam Ahamad', Rezai Karim Khondker², Zahir Uddin Ahmed ${ }^{2}$, Fahian Tanin ${ }^{3}$ \\ ${ }^{1}$ Research Division, Centre for Policy Dialogue, Dhaka, Bangladesh \\ ${ }^{2}$ Department of Economics, Shahjalal University of Science and Technology, Sylhet, Bangladesh \\ ${ }^{3}$ MSS in Economics, Shahjalal University of Science and Technology, Sylhet, Bangladesh \\ E-mail: \{mg.ahamad, rkhondker50\}@gmail.com, zahir-eco@sust.edu,fahian.tanin@gmail.com \\ Received December 3, 2010; revised March 12, 2011; accepted March 28, 2011
}

\begin{abstract}
This paper explores the major push-pull and self-selective factors of seasonal rural-urban migration during the lean period using survey data from northern Bangladesh. Among all other factors, probit estimates reveal that the choice of destination, per capita monthly food expenditure, availability of social safety net benefits are affecting individuals' decision of being seasonal migrant to a significant extent.
\end{abstract}

Keywords: Northern Bangladesh, Seasonal Unemployment, Voluntary Out-Migration

\section{Introduction}

The northern region of Bangladesh is a rather backward part of the country owing to, inter alia, its near absolute dependency on agriculture and almost non-existence of other significant sources of employment. Accordingly, rural-urban migration on temporary and voluntary basis frequently occurs in quest of employment due to seasonal unemployment during the lean period from mid- September to mid-November [1]. Furthermore, the region is also vulnerable to a wide variety of climaterelated shocks, e.g. frequent flood and resultant crop damage, river bank erosion, drought, etc. To reduce the risk emanated from income fluctuations mainly caused by seasonal unemployment, primary income-earners of many households temporarily migrate to outside of their usual working areas to diversified labor-intensive sectors of urban areas to smooth out income flow [2-4].

The growing incidence of temporary out-migration is a standard and voluntary coping strategy of the unemployed poor households. Therefore, voluntary out-migraon can be, and indeed is regarded as a significant risk-reduction strategy that explains the scale, duration and effectiveness of in-built 'push-pull factors' leading to voluntary outmigration [5]. The 'push' factors are mostly associated with the declining opportunities in agriculture, and 'pull' describes economic opportunities in urban-based industry and services [6,7] and comparative advantage to earn more in urban locations [8].
The objective of the study is to identify the major determinants of rural-urban migration of the seasonally unoyed during lean periods. Finally, different policy interventions will be explored. The major limitation of the study is mainly related to sample size. But according to the rule of thumb about sample size, it is likely to be acceptable.

\section{Seasonal Unemployment, Rural-Urban Out-Migration and Transformation of Household Income Patterns}

During seasonal unemployment rural poor's per capita income falls. Many of the poor are concentrated in norern areas such as the districts of Kurigram, Gaibandha, Nilphamari, Lalmonirhat and some part of Jamalpur district [9] (Table 1). For the most part, migrants are predominantly young, male household head and with marginal land ownership.

Voluntary migrants are sometimes referred to as 'economic migrants'. Furthermore, migration is 'selective' [5]. The reason behind this selectivity is that individuals respond differently to the prevailing factors associated with origin and destination areas. Reference [10] point out that seasonal migration takes place as an optimal endogenous response to individuals' comparative advantages of costs, returns, and welfare maximization and higher income opportunities which contribute to urban pull. Moreover, negative environmental conditions consistently encourage out-migration [11]. 


\subsection{Factor Affecting Seasonal Rural-Urban Migration}

Empirical evidence shows that northern districts in Bangladesh are economically weaker and per capita gross district product of these regions are far below the national average [12]. More than one-third of the households in these areas face food shortage throughout the year, and another one-third face temporary food shortage during the lean periods due to higher incidences of poverty compared to the rest of the country [13]. People of these areas take temporary migration during lean periods to maintain their income and consumption levels.

It is interesting to note that the greater Rangpur in the northern Bangladesh is a food surplus area, but agriculture alone cannot provide enough employment opportunities for the surplus agricultural labor force, which leads to a very low wage rate [14]. In 2004, the daily average wage for male laborers was found to be 50.9 BDT (Bangladeshi Taka) per day without meals that made up only $68 \%$ of the average wage rate in Bangladesh which was 74.5 BDT in other parts of the country [15]. This situation also stimulates to take temporary migration during the local lean periods.

Widespread flooding during this period intensifies this crisis every year. In accordance with the World Food Program's estimation, $80 \%$ to $90 \%$ of the people in this region are agricultural day laborers and they do not have any alternative source of employment during and immediate after any flood incidence. During this flood period, income earners of any vulnerable family try for alternate income generating activities taking temporary migration to urban areas. Moreover, rural demographic changes, low level of human capacities, changes in cropping patterns and intensities have significant impacts on the rural economic activities of the regions [16].

\subsection{Seasonal Out-Migration as a Livelihood Coping Strategy}

Rural poor optimally choose to migrate for short spells of time. The seasonal migrants, usually getting employed as wage labors at destination areas, can be grouped based on four pre-migration occupations. Table 2 indicates to the pre and post migration earning capacity and resultant changes. Reference [17] argued that migrants benefited from temporary migration by higher or regular income than their rural counterparts who do not migrate. Reference [17] point out that the livelihood strategies are heterogeneous. Migration, especially rural-urban, has long been a significant livelihood strategy of Bangladeshi rural inhabitants because rural poor can earn outside of their traditional sector [18]. The growing incidence of temporary movements also explains eventual returnigration following short duration of stay.

Table 1. Percentage of poor and extreme poor of the study area.

\begin{tabular}{|c|c|c|}
\hline Area & $\%$ Poor & \% Extreme Poor \\
\hline \multicolumn{3}{|c|}{ Upazila of Kurigram district } \\
\hline Bhurungamari & 68.20 & 52.00 \\
\hline Char Rajibpur & 73.90 & 58.80 \\
\hline Chilmari & 69.00 & 53.10 \\
\hline Phulbari & 65.80 & 49.10 \\
\hline Kurigram Sadar & 66.10 & 49.90 \\
\hline Nageshwari & 70.30 & 55.00 \\
\hline Rajarhat & 64.00 & 47.30 \\
\hline Raumari & 73.50 & 58.10 \\
\hline Ulipur & 66.90 & 50.00 \\
\hline Kurigram average & 68.63 & 52.59 \\
\hline \multicolumn{3}{|c|}{ Districts of northern region } \\
\hline Gaibandha & 53.04 & 36.07 \\
\hline Lalmonirhat & 53.46 & 33.82 \\
\hline Nilphamari & 70.15 & 55.00 \\
\hline Kurigram & 68.63 & 52.59 \\
\hline Northern region average & 61.32 & 44.37 \\
\hline Bangladesh average & 41.63 & 26.65 \\
\hline
\end{tabular}

Source: Bangladesh Poverty Map, VAM, 2009. 
Table 2. Changes in family income, before and after migration (\%).

\begin{tabular}{|c|c|c|c|c|c|}
\hline $\begin{array}{l}\text { Pre-migration } \\
\text { occupation }\end{array}$ & $\begin{array}{l}\text { Major occupation at } \\
\text { destination }\end{array}$ & $\begin{array}{l}\text { Economically active } \\
\text { people of the household } \\
\text { (\% of all members) }\end{array}$ & $\begin{array}{l}\text { Contribution to total } \\
\text { family expenditure } \\
\text { (pre-migration) }\end{array}$ & $\begin{array}{l}\text { Contribution to otal } \\
\text { family xpenditure } \\
\text { (post-migration) }\end{array}$ & Change \\
\hline \multirow{3}{*}{$\begin{array}{l}\text { Marginal } \\
\text { farmer }\end{array}$} & \multirow{3}{*}{$\begin{array}{l}\text { Wage labor \& } \\
\text { rickshaw puller }\end{array}$} & $1.00-1.99$ & 58 & 71 & $\uparrow 13$ \\
\hline & & $2.00-2.99$ & 65 & 79 & $\uparrow 14$ \\
\hline & & $3.00>$ & 72 & 89 & $\uparrow 17$ \\
\hline \multirow{3}{*}{$\begin{array}{l}\text { Agricultural } \\
\text { wage labor }\end{array}$} & \multirow{3}{*}{$\begin{array}{l}\text { Agri. \& non-agri. } \\
\text { wage labor }\end{array}$} & $1.00-1.99$ & 59 & 73 & $\uparrow 14$ \\
\hline & & $2.00-2.99$ & 64 & 75 & $\uparrow 11$ \\
\hline & & $3.00>$ & 70 & 86 & $\uparrow 16$ \\
\hline \multirow{3}{*}{$\begin{array}{l}\text { Non-agricultural } \\
\text { wage labor }\end{array}$} & \multirow{3}{*}{ Non-agri. wage labor } & $1.00-1.99$ & 62 & 81 & $\uparrow 19$ \\
\hline & & $2.00-2.99$ & 72 & 83 & $\uparrow 11$ \\
\hline & & $3.00>$ & 76 & 87 & $\uparrow 11$ \\
\hline \multirow{3}{*}{ Small business } & \multirow{3}{*}{$\begin{array}{l}\text { Wage labor \& } \\
\text { hawker }\end{array}$} & $1.00-1.99$ & 61 & 73 & $\uparrow 12$ \\
\hline & & $2.00-2.99$ & 69 & 81 & $\uparrow 12$ \\
\hline & & $3.00>$ & 74 & 88 & $\uparrow 14$ \\
\hline
\end{tabular}

*Eligible individuals who either are employed or are actively seeking employment.

\subsection{Migration as a Driver of Rural Transformation}

Seasonal migration can benefit areas of origin and destination, as well as migrants and their families. With all other stimulating factors, out-migration is a key process of rural transformation in the developing world. Thus, rural-urban temporary out-migration is a fundamental part of rural livelihood strategies and transformation. These reflect the push-pull effects of the northern areas and developed rural areas of Bangladesh in terms of economic development and regional endowments.

\section{Data and Methodology}

The empirical basis of this paper is a household survey conducted in 2009 in northern areas. A three-stage stratified random sampling, followed by a structured questionnaire was employed to collect micro-level data from nine different primary sampling units of study areas (Kurigram District) to obtain the required information regarding out-migration.

A probit model is used to identify the socio-emographic "push-pull” factors of individual's decision about the likelihood of undertaking voluntary migration. Related continuous explanatory variables, including binary response and composite dummy are considered to investigate and compare the probability of person's deci-

${ }^{1}$ See (Table 4). sion to voluntarily migrate to reduce income fluctuations ${ }^{1}$. The responses which are needed to construct the composite dummy (migrant's choice about destination area) is obtained by another three different dummy variables that are, availability of higher income sources, lower cost of migration, and favorable shelter at destination areas.

The zero-one response variable is used to estimate the probability that an individual is migrating, in the following way, whether an individual will decide to be an out-migrant with the value 1 represented by "go for temporary out-migration” and otherwise 0 .

$$
\operatorname{Pr}(y=1)=\Phi\left(\beta^{\prime} x\right)
$$

where $\operatorname{Pr}$ denotes probability and $\Phi$ is the cumulative density function of the standard normal distribution with $\varepsilon \sim N(0,1)$, which gives us the likelihood for both cases $y=0$ and $y=1$; and $\beta^{\prime} x$ is called the probit score/index. A one-unit change (either increase or decrease) in the $x$ coefficient leads to a change in the probit score/index by $\beta$ standard deviations. Table 3 describes the definitions of the model variables.

\section{Results and Discussions}

This paper estimated a probit model using continuous, single dummy and composite dummy for household, household head, area and migration characteristics to understand the selectivity of migration decision [19]. Here, age is positively related to the seasonal migration 
decision, whereas the quadratic term remains negative that refers to a number of physical as well as socio- demographic factors [20]. This reveals that the seasonal migrations occur frequently at early stage of life, and also reflects that migration decision increases with age of household head, and then decreases. Table 4 presents the results of the probit model with standard errors.

The second determining factor of the decision of being a seasonal rural-urban migrant is the individual's educational qualification. The primary education dummy (hh_tys_l) shows that individuals' who attended the primary schools have less probability to migrate during the lean period.

The model consists of the dummy variable "spcmfe_l" that equals 1 if the "spcmfe_l" does not exceed the lower threshold. A positive and significant "spcmfe_l” dummy shows that household with lower level of food expenditure has a probability of being seasonal migrant. Probit results also exhibit some significant impacts on total outstanding debt, enrollment in social safety net programmes and choice of destinations by the migrants.

Furthermore, total household members and the dependency ratio act as crucial determining factors for migration decision during lean period. Household head of a large family size have more probability to migrate than a smaller family head. The study shows that individual's with more family members or high dependency ratio has higher probability to be a seasonal rural-urban migrant during lean periods than his counterparts.

Households' need to take loan frequently to cope up with reduced income level due to seasonal unemployment, viable alternative income generating opportunities (leads to consume less food) and other basic needs during any lean period. The regression result of debt dummy shows that households' who have outstanding debt have a tendency to migrate more.

Moreover, households living in the mainland are less likely to go for temporary migration during the lean period than those living on riverbanks (Table 4).The study also reveals that urban areas with better opportunities attract more such migrants than cities as income opportunities are comparatively higher there. The dummy of "cho_des_l” shows the same. Table 2 reflects that income earnings of the migrants' families increase after migration take place compare to pre-migration periods.

\section{Conclusions and Policy Recommendations}

Individual rural-urban migration decision is modeled here using micro-level data, focusing on "push-pull” factors and self-selectivity of migrants due to seasonal unemployment from northern Bangladesh.

Conclusion 1: Seasonal rural-urban migration occurs frequently at early stage of life of an individual and then decreases with age.

Table 3. Descriptions of variables of probit model.

\begin{tabular}{|c|c|c|}
\hline Explanatory variables & Type & Description \\
\hline \multicolumn{3}{|r|}{ Household head's characteristics } \\
\hline hhh_age & Continuous & Age of household head \\
\hline hhh_age_sqr & Continuous & Age squared \\
\hline hh_tys_l & Binary & 1 if household head attended primary school, otherwise 0 \\
\hline \multicolumn{3}{|r|}{ Household characteristics } \\
\hline spcmfe_l & Binary & 1 if household's share of per capita monthly food expenditure exceeds lower threshold, otherwise 0 \\
\hline tot_mem & Continuous & Total household member \\
\hline dep_rto_l & Binary & 1 if dependency ratio is equal to or more than one, otherwise 0 \\
\hline hh_debt_l & Binary & 1 if household have outstanding debt, otherwise 0 \\
\hline ssnp_l & Binary & 1 if household under social safety net programmes, otherwise 0 \\
\hline \multicolumn{3}{|r|}{ Area characteristics } \\
\hline river_bank & Binary & 1 if household lived in riverbank, otherwise 0 \\
\hline \multicolumn{3}{|r|}{ Migration characteristics } \\
\hline cho_des_l & $\begin{array}{l}\text { Composite } \\
\text { Dummy }\end{array}$ & 1 if individual have favorable choice of destination, otherwise 0 \\
\hline hh_chn_l & Binary & 1 if migrant's income increases after migration, otherwise 0 \\
\hline
\end{tabular}


Table 4. Probit regression results of migration decision of household head.

\begin{tabular}{|c|c|c|c|}
\hline Explanatory variables & Description & Probit estimates & Std. Err. \\
\hline \multicolumn{4}{|c|}{ Household head's characteristics } \\
\hline hhh_age & Age of household head & 0.02 & 0.05 \\
\hline hhh_age_sqr & Age squared & -0.00013 & 0.004 \\
\hline hh_tys_l & 1 if household head attended primary school, otherwise 0 & -0.10 & 0.43 \\
\hline \multicolumn{4}{|c|}{ Household characteristics } \\
\hline spcmfe_l & $\begin{array}{l}1 \text { if household's share of per capita monthly food expenditure not exceeds lower } \\
\text { threshold, otherwise } 0\end{array}$ & $3.15^{*}$ & 1.79 \\
\hline tot_mem & Total household member & 0.08 & 0.13 \\
\hline dep_rto_l & 1 if dependency ratio is equal to or more than one, otherwise 0 & 0.50 & 0.39 \\
\hline hh_debt_l & 1 if household have outstanding debt, otherwise 0 & $0.03^{*}$ & 0.32 \\
\hline ssnp_l & 1 if household under social safety net programme, otherwise 0 & $0.58 *$ & 0.32 \\
\hline \multicolumn{4}{|c|}{ Area characteristics } \\
\hline river_bank & 1 if household lived in riverbank, otherwise 0 & 0.27 & 0.35 \\
\hline \multicolumn{4}{|c|}{ Migration characteristics } \\
\hline cho_des_l & 1 if individual have favorable choice of destination, otherwise 0 & $2.23^{* * *}$ & 0.53 \\
\hline hh_chn_l & 1 if migrant's income increases after migration, otherwise 0 & -0.50 & 0.36 \\
\hline cons & Constant & $-4.57^{* *}$ & 2.24 \\
\hline LR chi2(11) & & 46.76 & \\
\hline Prob > chi2 & & 0.0000 & \\
\hline Pseudo R2 & & 0.3203 & \\
\hline Log Likelihood & & -49.62 & \\
\hline Observation & & 106 & \\
\hline
\end{tabular}

Notes: Dependent variable: Migration decision of household's head. $* * *<0.01, * *<0.05, *<0.10$.

Conclusion 2: Choice of favorable destinations consisting availability of higher income opportunity, lower cost of migration, and the favorable shelter at destination areas are significantly related to individual decision of being a migrant.

Conclusion 3: Lower per capita food expenditure is another determining factor of voluntary migration.

Conclusion 4: The probability of temporary migration decreases, if migrant's income increases after the migration is taken place.

Short term: In view of the upcoming momentum of seasonal unemployment, short term measures (employment/income generating programmes, social safety net etc.) before the onset of the lean period may increase resilience to preliminary shocks from socio-demographic constraints and subsequent fluctuations of income.

Medium term: Linked channels of connectivity involving strategic/buffer stock of food at the Upazila level, convenient supply chain management and allocation of sufficient food aid may reduce seasonal difficulty.

Long term: Investment in agro-based industries is also likely to generate employment opportunities which would reduce the seasonal unemployment in northern regions.

To conclude, voluntary out-migration, apparently a li- velihood strategy of the poor that changes household's income following rural transformation to accommodate with wage differentials, reduces consumption risks.

\section{Acknowledgements}

This paper is an outcome of the corresponding author's MSS thesis under a research project, sponsored by Food and Agriculture Organization (FAO) and was conducted by the Department of Economics, Shahjalal University of Science and Technology. Authors were members of the research team. We would like to thank the anonymous referees and Dr. A. K. M. Nazrul Islam for their helpful comments. The other usual disclaimers apply.

\section{References}

[1] S. Zug, "Monga-Seasonal Food Insecurity in Bangladesh-Bringing the Information Together," The Journal of Social Studies, No. 111, July-September 2006, Centre for Social Studies, Dhaka.

[2] E. Ravenstein, “The Laws of Migration," Journal of the Statistical Society of London, Vol. 48, No. 2, 1885, pp. 167-235. 
[3] D. B. Grigg, "E. G. Ravenstein and the 'Laws of Migration',” Journal of Historical Geography, Vol. 3, No. 1, 1977, pp. 41-54. doi:10.1016/0305-7488(77)90143-8

[4] O. Stark, M. Micevska and J. Mycielski, "Relative Poverty as a Determinant of Migration: Evidence from Poland,” Economics Letters, Vol. 103, No. 3, June 2009, pp. 119-122. doi:10.1016/0305-7488(77)90143-8

[5] E. S. Lee, “A Theory of Migration,” University of Pennsylvania, Pennsylvania, 1966.

[6] P. Deshingkar and S. Grimm, "Voluntary Internal Migration: An Update,” Overseas Development Institute (ODI), London, 2004.

[7] G. L. Clark and K. Ballard, "Modeling Out-Migration from Depressed Regions: The Significance of Origin and Destination Characteristics," Environment and Planning A, Vol. 12, No. 7, 1980, pp. 799-812. doi:10.1068/a120799

[8] B. J. Riadh and M. Hassen, "Rural-Urban Migration and Self-Selection in Tunisia," Papers in Regional Science, Vol. 77, No. 4, 1998, pp. 347-360.

[9] VAM, “Bangladesh Poverty Map 2009,” Bangladesh Bureau of Statistics and Vulnerability Assessment and Mapping Unit, Dhaka, 2009.

[10] O. Stark and S. Fan, "The Analytics of Seasonal Migration,” Economics Letters, Vol. 94, No. 2, February 2007, pp. 304-312.

[11] L. Van Wey, "Land Ownership as a Determinant of International and Internal Migration in Mexico and Internal Migration in Thailand," International Migration Review, Vol. 39, No. 1, 2005, pp. 141-172. doi:10.1111/j.1747-7379.2005.tb00258.x

[12] S. Zug, "Monga-Seasonal Food Insecurity in Bangladesh,” NETZ, Dhaka, 27 May 2010.
http://www.bangladesch.org/pics/download/S_Zug_Articl e_Monga.pdf.

[13] Q. Shahabuddin and Z. Ali, "Natural Disasters, Risks, Vulnerability and Persistence of Poverty: An Analysis of Household Level Data,” PRCPB Working Paper No. 15, Bangladesh Institute of Development Studies (BIDS), Dhaka, Bangladesh, 2006.

[14] M. Kabir, "Conceptualization and Measurement of Food Insecurity: The Context of Bangladesh,” BIISS Journal, Vol. 26, No. 1, 2005, pp. 55-90.

[15] BBS, “Statistical Yearbook of Bangladesh 2005,” Bangladesh Bureau of Statistics, Dhaka, 2005.

[16] U. K. Deb, A. K. M. N. Islam, N. Khaled, A. Nabi, M. Al Amin, M. G. Ahamad, K. Tasnima and D. N. R. Paul, "Vulnerability to Climate Change: Adaptation Strategies \& Layers of Resilience in Bangladesh,” Paper Presented at International Workshop on Building Climate Resilient Agriculture in Asia, Dhaka, 5-6 May 2010.

[17] P. Deshingkar and S. Akter, "Migration and Human Development in India," Human Development Research Paper 2009/13, UNDP, 2009.

[18] T. Siddiqui, "Migration as a Livelihood Strategy of the Poor: The Bangladesh Case," DFID-RMMRU Conference on Migration, Development and Pro-Poor Development Choices in Asia, Dhaka, 2003.

[19] M. Z. Hossain, "Rural-Urban Migration in Bangladesh: A Micro-Level Study,” For Presentation in a Poster Session on Internal Migration at the Brazil IUSSP Conference during 20-24 August 2001.

[20] N. H. Chau, "The Pattern of Migration with Variable Migration Cost,” Journal of Regional Science, Vol. 37, No. 4, 1997, pp. 173-176. 